\title{
Gaining through Bereavement: A Comparative Study of the Literature of Bijan Najdi and Gabriel Garcia Marquez
}

\author{
Zahra Sonia Barghani
}

Email: Z.barghani25@gmail.com

Mitra Toyour

Email: Toyour1967@gmail.com

\author{
Doi:10.5901/mjss.2017.v8n1p478
}

\begin{abstract}
Throughout human history bereavement has always imposed its undeniable and inevitable impact on the life of those affected by it. Despite all discrepancies what can be considered the common ground in bereavement among all nations regardless of cultural, ideological, religious and ethical values is the fact that bereavement infuses an indispensable change into the lives of those encountering it. The comparative study of Burial and The Handsomest Drowned Man in the World by Iranian and Colombian authors, respectively, points out the unconventional reversed handling of bereavement which results in obtaining insight into the human capacity to mature. Both authors make their characters inseminate their barren lives with grief to produce a change which is drastic and flourishing in Gabriel Garcia Marquez and soothing and stabilizing in Bijan Najdi. Through the course of the stories the childless couple in Najdi and the villagers in Garcia Marquez are gradually exposed to the truth of their lives ironically by the corpses coming up their ways quite unexpectedly and learn to develop new identities, attaching themselves to and possessing the bodies. This comparative study sheds light on how the revelation they experience inculcates a joyful, fluid mobility in the villagers and stability in the couple's life. The study of these texts reveals the absolute notion that the actual change originates from the world within and what lies in the world without is dead.
\end{abstract}

Keywords: Death, Bereavement, Bijan Najdi, Gabriel Garcia Marquez

\section{Introduction}

An inseparable part of human life is loss and the grief and bereavement that follow. Psychologists, psychiatrists and counselors have studied the causes, stages and results of individuals who go through bereavement for decades. Understandably, the universal human phenomenon of loss has found its way into literature; this is not surprising because literature is a reflection of human trials and triumphs. From Dostoevsky to John Green we have witnessed stories that portray human loss and the emotions, actions and revelations that materialize after loss. Bereavement and loss are universal topics that transcend time, place and culture; thus this study analyzes 2 contemporary short stories and sheds light on how the characters from two seemingly different contexts grieve similarly and reach revelations of their own kind. The stories are from Iranian and Colombian writers Bijan Najdi and Gabriel Garcia Marquez, respectively.

The short story Burial by Bijan Najdi and The Handsomest Drowned Man in the World by Gabriel Garcia Marquez both depict the process of loss which the characters face. In a glance, the stories do not present any significant similarities. However, with a deep analysis in line with various bereavement theories, these stories cross at the fine point of tranquility after self-created loss. Through the study of Najdi and Marquez's work it is discovered that the characters within these stories induce loss on themselves resulting in the construction of a new identity. Through the ownership of a loss the characters develop and mature. In her book On Death and Dying Elisabeth Kübler-Ross discusses the steps experienced by those dealing with death; she writes "Denial...Anger...Bargaining...Depression...Acceptance" (KüblerRoss, 1970, p. 78). Contrary to Ross's statement, in these stories loss does not form a phase of denial, isolation or fragmentation but rather it creates a new identity and transforms the meaning of life for them.

\section{Methodology}

The study looks at two short stories, one by Bijan Najdi and the other by Gabriel Garcia Marquez, and analyzes the concept of personal evolution through the reversed handling of bereavement. This study sheds light on the process and 
outcome of the bereavement of the main characters within these stories and how from barren existence mobility or stability, depending on the situation, can result. Through the evaluation of the text and under the scope of recent literary and psychological research, this competitive study leads to an innovative understanding that actual change is an inside out transformation.

\section{Discussion}

\subsection{Burial}

Bijan Najdi( 1947-1997) is an Iranian writer most famous for his short story collection The Leopards Who have Run with Me published 3 years prior to his death. The 10 story collection received the Gardoun Award and was recognized as "one of the best short story collections ever written in Iran" (What's, 2015). Behnaz Salehi and Seyed Babak Farizani (2016) describe his work as "Najdi's works seem ordinary and natural. His style of narration and his view about the living and dead, draws the reader into the enchanting and noble realm of his stories. His stories begin when fiction and reality are juxtaposed."( Salehi and Farizani, 2016, p. 134).

The story examined in this study is the first story of The Leopards who have run with me and revolves around a couple and follows one odd day in their life. The story, similar to other Najdi's stories has a very simple and nontechnical language. Maliheh and Taher are introduced as any normal couple; Taher singing in the shower and Maliheh setting the breakfast cloth. It is after the sound of an ambulance that they rush to the window and the notion of corpse is introduced to the readers."I hope it's not a corpse again... They must have found a corpse again." Followed by Maliheh's insistence "A dead body... Everyone's going to have a look at it, get up."

The fast paced story moves to the place where the corpse was found and we are introduced to another facet of Maliheh's personality; her determination and desire to know whether the body belonged to a child or adult. As if it was not already evident to the readers that Maliheh has had a previous tragic experience regarding death and has a lack of being a mother, Najdi highlights Maliheh's inner desire in the following lines of the story.

A man leaning on the railing of the bridge said: "I saw him. He was all blown up and dark. It was a kid, Mother, a little one."

Taher took Maliheh's arm. The bridge and the man and the river swirled around her. All that could be seen of the jeep was some dust moving towards the village.

"This man called me Mother, did you hear Taher? He called me..."

With Maliheh's insistence the couple goes to the local doctor and inquires about where the dead body will be kept and what will come of it? She asks the doctor with childish eager "If nobody comes, if nobody claims him, can we take him?". Maliheh's need for a child and her desire to possess one despite logic are apparent; Taher knows but cannot wrap his mind around why she possesses such a need, asking her "Take the child with us? What for, Maliheh?"

Najdi ends the story with a slight open ending; no one comes for the corpse and Maliheh and Taher are seen in the clinic cemetery present at the burial. They watch the body be buried and as they head home Maliheh comments that "So he belongs to us now, no? Now we have a child who's dead...". Maliheh has tried extremely hard to fill her lack, the blank space in her heart, with the dead body, requiring the affirmation of her husband in their ownership of a child, even a dead one.

\subsection{The Handsomest Drowned Man in the World}

The Handsomest Drowned Man in the World is a short story from the collection Leaf Storm and Other short stories by the acclaimed Colombian writer Gabriel Garcia Marquez. The story is set in a small coastal village. The very description of the setting of the story pinpoints the sterile condition of the life of the villagers.

The village had barley twenty houses made of planks, with flowerless stone porches, scattered across the back of a deserted cape. The earth was so barren that mothers always went in fear that the wind would carry off their children, and they had to throw their deceased, continually taken by the years, from the cliffs.

They place their dead in the sea to have enough space for the living but the barren land is deprived of actual life. Ironically, it is a corpse that rescues them and enlivens their world.

One day a group of children found a drowned man; they ran to the beach and "they peeled off the thickets of seaweed, the jellyfish tentacles and the rest of the tattered cloth and driftwood it carried, and only then did they discover that it was a drowned man."(1). The men carried it to the nearest house and only then did they notice his significant height and weight. 
That night when the men go to find out if anyone from the neighboring villagers is missing, they leave the body with the women to tend to it. Having cleaned the corpse off of seaweed and mud, they stand with awe and begin fantasizing and making up stories around him. It is through these stories that they realized how incompetent their imaginations are. He is the tallest, strongest and most virile man they had even seen. They start to imagine him when he was alive noting " that if that magnificent man had lived in the village, his house would have had the widest doors, the tallest roof and the firmest floor, and the frame of his bed would have been made of giant timbers with iron bolts, and his wife would have been the happiest."(2).

The villagers were so captivated by his magnificence that the women even began to regard him as the source of every change happening in their world. "The wind had never been so sustained nor had the Caribbean been so unsettled as on that night, and they supposed that these changes had something to do with the dead man". Their fantasizing and their comparison of the great corpse again their only people crossed the boundaries of their imagination. The villagers became exposed to a new level of revelation and they notice the insignificance of their lives and their barren world. Diana Fosha comments on the effects of trauma like the one the villagers are experiencing and writes "Trauma transforms. Certainly for bad, but also for good. And it is precisely that huge transformational potential that we want to harness for our own aims." (Fosha,2001, p.4).

The villagers named the body Esteban to make him their own. "Praise the lord" they sighed "he's ours". The sense of possession following the attachment they had assumed for the drowned man gave way to emotional outbursts and the women went from "sighs to laments, and the more they wept the more they felt the desire to cry, for the drowned man was becoming to them more and more Esteban, until they wept so for him that he was the most helpless man on the earth".

The men who were bewildered by the women's fuss over the corpse hurried to send the body back to the sea and tried to improvise the means to make sure this time it would not wash up on any shore. Meanwhile, the women fretted about and decorated the dead body to mask their grief and stall the men's work. "The women continued digging up their cheap relics, carrying and bringing, tripping, going with sighs if not tears. On the men's objection to their conducts the women revealed the drowned man's face to them and "then the men too remained breathless". Since the onwards, men shared the women's grief and even the most mistrustful ones felt for Esteban sincerity. They arranged the most splendid funeral for him along with the people from the neighboring villagers. The dead man had given them full insight into "the desolation of their streets, the aridity of their courtyards, the narrowness of their dreams.". He had broadened their horizons, reshaped their world and expanded their imagination and finally given them a new identity. Feeling selfsufficient enough, the villagers felt ready to become detached from Esteban and let go of him. They sent him back to the sea where he belonged unanchored "so that he could return if he wished, and when he wished, and everyone held their breath during the fraction of centuries that it took for the body to fall into the abyss.".

\subsection{A Comparative Survey}

\subsubsection{Sense of Lack}

The short stories Burial and The Handsomest drowned man in the world both depict a sense of lack hidden inside their characters. Lack differs in each of the two stories and the stories do not overtly exhibit a parallel. However, since lack itself holds various meanings, the stories can be interpreted to reveal a similar message. Sigmund Freud describes lack as "longing for the lost object" (Freud, 1917) or "guilt over negative feelings toward the lost object, especially in the case of death" (Freud, 1917). Georg Wilhelm Friedrich Hegel defines lack as the object "being the necessary condition for the maintenance of desire, a lack in being that strives to be filled through the (impossible) attainment of an object."(qtd in Genosko, 2001, p. 1447). For psychologists and thanatologists, lack often shapes after death and trauma. In the first chapter of her book Dying, Death and Grief: Working with Adult Bereavement Brenda Mallon looks at loss from a different perspective stating "Evidence indicates that where we can find meaning in the experience of loss we are more likely to experience positive adaptation." (Mallon, 2008, p.12).

In the paper Attachment Theory, Loss and Trauma: A Case Study, Mariana A.Zelenko and Anne Benham of Stanford University School of Medicine write that awareness of the loss process is needed for the successful recuperation of the bereaved; "This awareness helps ... and possibly prevent a negative impact of the loss on the developing personality."(Zelenko and Benham, 2002, p. 204)

The lack that Maliheh is feeling in Burial is conscious; through her dialogues, Najdi's description and her actions, it becomes evident to the readers that Maliheh is aware that she needs this dead body to feel alive again. Najdi depicts her thoughts and exposes her desire for child "Maliheh was thinking, if only there were children here instead of all these 
trees.". Later when they visit the local doctor in response to Taher's startled inquiry about why, Maliheh responses "We will bury him, we will bury him ourselves. Maybe then we can love him. Even now, it's as if, as if... I love him...". Maliheh exhibits a desire for love; she is caught in a desire to possess a child and call it her own.

In The Handsomest drowned man in the world lack is prevalent within the villagers in a different sense than that of Maliheh. Described as "The village had barley twenty houses made of planks, with owerless stone porches, scattered across the back of a deserted cape." ; the village is lifeless and vacant. The lack of the villagers is not conscious, as in Burial, from the beginning of the story they don't exhibit any reflection on their way of life. Garcia Marquez uses the village as a metonymy of the villagers stating "The earth was so barren that mothers always went in fear that the wind would carry off their children.". The barren earth is actually a barren sterile life and imagination; the villagers suffer from a deadly lack of ideas and vibrancy. In Contemporary Approaches in Literary Trauma Theory, Michelle Balavea writes "Trauma is a lived experience, one that is identifiable to a greater or lesser degree."(Balavea, 2014, p.7). She goes on to note that "depicts of trauma in literature cultivate a wide variety of values that reveal individual and cultural understandings of self, memory and society." (Balavea, 2014, p. 8). Balavea's understanding of trauma defines Gabriel Garcia Marquez's creation of the villagers in The Handsomest drowned man in the world as an object to experience the trauma of the death of imagination and reveal the cultural importance of imagination.

\subsubsection{Stagnancy and Transformation}

Burial and The Handsomest Drowned Man in the World both represent change and transformation; each story illustrates the development of its characters from the void of meaning to meaningful existence. In Burial Maliheh is battling a constant struggle within herself of who she is without a child. She cannot define herself in any terms other than as a mother; thus without a child she is lost and bewildered. Tony Walter notes that part of grief is construction of identity "that enables the living to integrate the memory of the death into their ongoing lives." (Walter. 1996, p.7). The Handsomest Drowned Man in the World the villagers live a stagnant existence prior to the finding of Esteban and find a new identity after him. The drowned man who washes up on their shore ignites their change from a village of lifeless creatures to owners of imagination and development. Najdi and Marquez's short stories form a link in the sense that they both illustrate change within their characters. The source, result and path of the transformations are different but they exhibit distinct parallels. The passage through change acts a bridge for the characters to move from lack to ownership.

The journey of change for Maliheh and the villagers both starts from stillness. Stagnancy is the fuel which lights the change for both stories. Maliheh is trapped in a dormant stage much the same as the villagers are in Garcia Marquez's short story. Both sets of characters lack something within themselves and are now drowning in this void. Freud believed that humans have five stages of psychosexual development and only with the successful passage through each phase will they reach normal adulthood. The libidinal energy of "the individual can become fixated or regressed if any of the earlier developmental stages is marked by either overindulgence or trauma. In other words, such a person's libidinal energy remains locked within a less mature stage."(Freud, 1917, p.112 ). The villagers have a similar mystification and stagnancy; however, as they are a community their sense of lack differs in a communal sense. The villagers in The Handsomest Drowned Man in the World suffer from a lack of imagination and are caught in a state where the psyche is alive but vibrancy of the mind has ceased to exist. It is at the funeral of Esteban that the villagers openly own their lack for the first time, "the men and women became conscious for the first time of the desolation of their streets, the aridity of their courtyards, the narrowness of their dreams". The same as Maliheh, the villagers are dealing with a lack of life; they lack a spirit to motivate them to move on and embrace life.

The very essence of lack creates stagnancy in the life of the characters. Maliheh and Taher's town is described as "minus 11, theirs was the coldest part of the country" and "Maliheh was too tired to sing the forgotten songs of Qamar through her dentures" .Najdi's descriptions illustrate a dormant setting with frozen potential. Marquez's villagers occupy a similarly torpid village, described as having "flowerless stone porches" and "The earth was so barren." Both husband and wife in Burial and the villagers in The Handsomest Drowned Man in the World are trapped in a passive existence and must overcome this to lead a productive life. The characters in Najdi's book are dealing with a lack of child. Maliheh is quick to ask the doctor the question of "If nobody comes, if nobody claims him, can we take him?", referring to the child's corpse. In The Handsomest Drowned Man in the World the villagers are dealing with a lack of life; they need a spirit to help them acknowledge their full potential and embrace life.

Through the course of the stories, both sets of characters develop and mature. They create a new identity for themselves; Maliheh becomes a mother, giving her peace and tranquility and the villagers become the kinsmen of the great Esteban, which unites them as a community. One psychologist notes the recreation of identity as "the bereaved their sense of identity may have to be redefined...the experience may lead to greater maturity and a deeper sense of 
understanding." (Mallon, 2008, p.7), while another writes "Trauma will be resolved, not only by setting things right in the world, but by setting things right in the self." (Alexander, 2002, p.5).

Najdi's characters create a loss of child to help sooth their lack. They strive to own a deceased child to give them a new identity. Maliheh fears losing her artificial loss because it is her savior; the corpse can give her the identity and attachment that she desires. In the chapter Attachment and Loss, Death and Dying Mallon writes "For the bereaved their sense of identity may have to be redefined." (Mallon, 2008, p.7). Maliheh wants to define herself as a mother, although she lacks the needed object of motherhood.

The couple's awareness of the stagnancy they are caught up in and their conscious effort to release themselves from their current situation instigates the notion of inducing trauma on themselves in order to seek life in a corpse. The fact that the idea of bereavement calls for possession in the first place is the key factor in initiating their move. Maliheh and Taher desire the ownership of a child to help them move on.

The villagers in Garcia Marquez's tale are bewildered in the barren world of their village until a corpse, their saver, is washed up on their shore. Without their consciousness it penetrations through their minds and souls and enlivens their dead lives. Here again their induced trauma provokes life and relief. Esteban awakens something within the villagers; he enriches their imaginations and forms never before created thoughts within their minds. "They also knew that everything would be different from then, that their houses would have wider doors, taller roofs, firmer floors.". The villagers also decided "they would paint the fronts of their houses with joyful colors to eternalize the memory of Esteban.".

The villagers in The Handsomest drowned man in the world are in need of a transformation; different from that of Maliheh for she needs to own an object while they need imagination. Lack of child and lack of imagination parallel the stories of Bijan Najdi and Gabriel Garcia Marquez by initiating great transformation from stillness and loss. This process is not uncommon as in an article titled Trauma the Roots of Resilience Diana Fosha discusses how difficult times, deep despair and a shattered world can actually propel the broken into better understanding and as a result peace. She writes "The therapeutic combination of affirmation and personal engagement help get through the breakthrough, the nature of the breakthrough being a powerful emotion." (Fosha, 2001, p.10) Both sets of characters are experiencing this powerful emotion and breaking through to a new more complete self.

\subsubsection{Sense of Possession}

A process that starts with a sense of lack and is followed by self-induced trauma leads Maliheh and the villagers to salvation; each of their own type. A closer look at the bereavement processes of both characters shall make the analogous factors clearer. Najdi's characters go through a bereavement phase preceding their conscious understanding that Maliheh posses a lack. Malhieh's need to own a child and thus fill her need of child is clearly shown in the following lines of the story.

"We will bury him, we will bury him ourselves. Maybe then we can love him. Even now, it's as if, as if... I love him..." Maliheh buried her head in her chador and the cry that she had kept from the bridge to the clinic broke out and her thin shoulders twisted under her chador and she blew her nose into her covered fist.

Maliheh needs ownership and attachment. A conventional desire according to Mallon who writes "It is important to understand attachment since it is essential for healthy emotional growth and for building resilence."(Mallon, 2008, p.5). Maliheh takes an unconventional path to obtain this emotional growth; she first losses it and then owns it. Maliheh's strive is not for a child but rather the ownership and attachment to one. She embarks on this process to cure her lack but recognizing what she is missing. Her lack drives her to extreme lengths, she is even physically deteriorating as a doctor's visit results in the following lines. "Doctor Yavari shook Taher's hand and asked Maliheh: "Have you been taking your pills?" and "The doctor had Maliheh lying down on a wooden bench. He stuck a thin needle under the skin of her hand." Once the object of ownership is found the lack transforms to loss, and all the mental and physical strains cease to exist.

Once Maliheh posses a child of which she claims she has lost "So he belongs to us now, no? Now we have a child who's dead..." her lack diminishes. She no longer has a deficiency in her identity as a person for now she is a "mother" in the bereavement phase for she has lost a child. do not grieve or go into denial rather they jump to acceptance of their loss; which is obviously what they were aiming to do in the first place. Through this ownership of the corpse and its burial the couple reaches a sense of relief. They are satisfied with the possession of a dead body. This explains why the couple was so keen to name the body; naming proves to be the step into ownership. This dead body is the answer to their prayers for it gives them a sense of satisfaction and covers their lack. The story does not continue after the burial therefore we do not know if the couple can actually grow and heal. But in terms of bereavement they grief is a painless way, because they bury the pain they are have induced on themselves. The body symbolizes their lack and with its placement in the ground the couples seems to have passed through bereavement successfully. Happiness in their own 
terms is obtained.

In Gabriel Garcia Marquez's tale the characters possess an unconscious sense of lack and go through artificial loss to gain happiness. But their happiness differs greatly from the characters in Najdi's work because it leads to revelation. The villagers develop as better people after Esteban because the dead corpse makes them aware of their inner ideas and it expands their imagination. The villagers now hopeful of life planned and imagined the future.

They would paint the fronts of their houses with joyful colors to eternalize the memory of Esteban, and they would break their backs digging springs from the rocks and sowing flowers on the cliffs, so that in the dawns of the coming years the travelers on great ships would awaken suffocating on the aroma of gardens on the high sea.

\subsubsection{Recognition and Self-Reconstruction}

The villagers grow because for the first time they reach a state of consciousness about their lack; they understand how closed their village and ideas had been. They realize the misery of their previous condition and through the loss of Esteban, who was never actually theirs; they reach a new state of growth. The villagers become self-sufficient and let go of Esteban because they feel complete even without him. They give him back to the sea because as Michael Vannoy Adams writes "In Jungian terms, the sea is the image of the unconscious." (Vannoy Adams, 2014, p.174) and Esteban has done his job and healed their lack and now they can move on without him. Moreover, Mallon notes "The relationship with the deceased continues in the bonds we have with them" (Mallon, 2008, p.14). The villagers learn to appreciate as well as love life and its beauty and develop through this. Walter writes that "The deceased give advice and guidance and the deceased provides basic values in life that are emulated." (Walter 219).

The processes of change that Najidi and Garcia Marquez's characters experience differ in style, context and pace. Both stories depict a series of events that link together to lead the characters from stagnancy to a new understanding. The villagers step into this realm of self-discovery with the sound of the children's shouting from the shore signaling a new occurrence and a new presence on their island. The fact that the children find the body as opposed to the adults symbolizes an open imagination. The children remove the seaweed off the dead body and seem to polish the residue of the ocean off it. The newly cleaned corpse illustrates the spirit of the city which desires rejuvenation as well. In Burial the events which lead to Maliheh's peace of mind start with the sound of the ambulance siren informing the public of a death. Maliheh, unlike the villagers, is aware of her lack from the beginning and the siren grabs her attention to the body with which she might be able to heal her pain. The sound of the children's cries on the island and the sound of the siren outside the couple's window both depict the start of something new, something which ignites change.

After the finding of the death body the children inform the villagers, first women and then men, to join in embracing their new discovery. The villagers fantasize the previous whereabouts of the body and gradually expand their imagination to places they did not know existed. It is through the expansion of their thoughts and phrases such as "They also noticed that he bore death with dignity" and "they become conscious of the sort of man he was, and then they remained, breathless." that the villagers slowly reach the realization that what they had considered a perfect life was actually the creation of their incompetence. With the help of the dead corpse, a part of their mind which had been dormant starts to awaken, leading to the villagers' realization that they possess an incompetence of imagination. It is at this stage that they first consciously recognize their lack. The realization of lack in Najdi's story differs for Maliheh does not spend any time in the discovery and acceptance of the lack; the story starts with her conscious desire to find a dead body which she can own. Maliheh's urgency to run to the bridge or follow the corpse depicts her despair. She even starts to fantasize about her newly obtained object of possession pondering upon future issues with sentences such as "We must tell them to carve a stone for him." and "We must find him a name."

The villagers do fantasize about the corpse but at a slower pace than Maliheh, for Maliheh already knew what she needed while the villagers reach that phase as the story goes on. The transformation of the villagers first finds physical form before penetrating into their minds and spirits. "The wind had never been so sustained nor had the Caribbean been so unsettled as on that night". This part of the story is the climax of the revelation; the restless ocean symbolizes the restlessness of a soul trapped within an immature mind.

The villagers in The Handsomest drowned man in the world feel a change, still unknowing of its true source, they relate it to nature. As they continue their fantasizing about the corpse's past and identity they reach a critical phase in possession. They want to name him. Naming an object or person is a key step in the recognition of one's ownership and a huge milestone in the attachment of a person. "The oldest of the women, who by being the oldest had contemplated the drowned man with less passion than compassion, sighed: "He has the face of one who's called Esteban."

Maliheh is conscious that she needs a name to establish possession. She has given herself the sense of ownership from the beginning; she ponders on a name before even seeing the body. Maliheh is already ahead in the 
attachment relationship possessing worry and concern about the death body. Her sense of ownership and attachment to the body are so strong that she already worries of the loss of the object she does not yet even own. Maliheh's mental trauma is so severe that she even panics and feels desperation from the idea of loss. Van Dyne and Pierce study the importance of name, ownership and belonging and write "a wide variety of fields emphasizes the importance of possessions and ownership in influencing human attitudes, motivation, and behavior...and links to self-identity, selfadjustment, and well-being." (Van Dyne and Pierce, 2004, p.440). Both the villagers and Maliheh's losses exists within their imaginations and yet they possess the value of that loss with all their might. They need to own it in order to reach a new self-identity and well-being.

Maliheh and Taher step into reality and out of their imagination near the ending of the story when they go to the cemetery to attend the ghostlike burial.

They sent the corpse from the clinic to the cemetery, carried on a crate, rolled up in a grey sheet. Outside of the clinic's courtyard, Maliheh and Taher, who were not dressed in black, in a weather that was neither sunny nor rainy, started to walk at a slower pace than the man who carried the crate.

The atmosphere is tranquil and stable. Maliheh and Taher are no longer trapped in the fragmented state of instability and bewilderment. They have found an object which has transformed their lack into a loss and acts as their path to change.

The villagers in The Handsomest Drowned Man in the World continue their process of change at a slower pace than that of Maliheh. They have acknowledged their lack and formed attachment to the dead body by naming it Esteban. Their formation of identity evolves as their minds start to operate in never before ways. They embrace previously insignificant notices such as colors and flowers, symbolizing their rebirth. The body symbolizes the death of their souls and also the flourishing of their imaginations.

Some women that had gone to look for flowers in the nearby villages came back with others who did not believe what they had been told, and these went for more flowers when they saw the dead man, and they brought more and more, until there were so many flowers and such a crowd that one could barely walk.

The villagers have arrived at a phase where they possess an ownership to Esteban. This possession develops the villager's identity and they construct themselves in relation to Esteban. Mallon comments that creating a biography is essential to growth, he writes "The purpose of grief involves the construction of a biography 'that enables the living to integrate the memory of the dead in their ongoing lives'" (Mallon , 2008, p.14). Having gained an identity they venture forward on their process of change. The villagers are using grief in the way Boerner and Hechkhausen note "Grief as a process of relearning our worlds in general and in particular relearning the relationship to the deceased." (Boesrner and Hechkhausen, 2003, p.204). The villagers call themselves the kinsmen of Esteban and redefine themselves in relation to the lost one.

The change the villagers experience is more transformative than Maliheh's because Esteban does not only heal their current situation he widens their scope. Esteban brings them to the realization that change comes from within and the path of life is formed from the inside.

Following the conscious ownership of Esbatan the transformation of the villagers' mentality and lifestyle gains speed. The change starts from the children, as children possess a clearer and purer imagination; the contagious sense of improvement then transcends to the women and finally after rigidness the men feel the power that Esteban has given as well.

There was such truth in his mode of being, that even the most suspicious of the men, those that felt bitterness during the long nights at sea that their wives would become tired of dreaming of them to dream instead of drowned men, even these, and still others who were much harder, shuddered to the marrow with the sincerity of Esteban.

Even men who are the last to embrace imagination and the most suspicious and bitter creatures feel for Esteban and all that he symbolizes. The villagers continue their journey to realization with a faster pace. They have felt the magic of Esteban as he has filled their hearts and their heads, filling a lack that till just recently they did not even know existed. The power of imagination and change shines through their eyes, it transforms their way of life and pours from the inside out. Esteban has expanded their views and has changes their life; he did not only heal their unknown pain but he taught them how to heal. In the story it's written "Everything would be different from then on, that their houses would have wider doors, higher ceilings, and stronger floors so that Esteban's memory could go everywhere without bumping into the beams."

The power of the loss of Esteban surpasses the loss of the dead child in Bijan Najdi's story in numerous ways. The most prevailing is the impact of the loss; for Maliheh the dead body fills her need to be a mother and thus, though untold in the story, seems to put her at ease. Esteban's corpse, however, goes beyond the feeling of ease and dives into mobility. The artificial loss of Esteban acts as a light whose flames have gained new fuel while the loss of the child's 
corpse suffocates the flames of Maliheh's despair. The ending of both tales illuminates this difference as well. In the Burial it is written that the funeral took place at a time when the "weather that was neither sunny nor rainy" and they "started to walk at a slower pace than the man who carried the crate, who changed it from one hand to the other from time to time". Gabriel Garcia Marquez writes "They released him without anchor, so that he could return if he wished, and when he wished, and everyone held their breath during the fraction of centuries that it took for the body to fall into the abyss". As evident in the excerpt "So he belongs to us now, no? ... "We must tell them to carve a stone for him." , Maliheh still needs the body, her sense of lack has changed to loss but now she desires to hold on to the loss because it modifies her identity. By placing the corpse in the ground she is establishing roots for herself; a safe haven and a place of reassurance. The villagers have surpassed the need for possession of Esteban and understand that the change Esteban brings is from within; Esteban has rejuvenated their souls and now they release him back into the sea. The funeral of the corpse is described as the body "rolled up in a grey sheet" and "grey, dusty" whereas the funeral of Esteban was described as "the most splendid funeral", and "there were so many flowers" with planned changes so "the memory of Esteban could walk everywhere". The stories end of different notes and leave the readers with different senses of the calm after a storm of loss; Maliheh is now glued together and satisfied with her new possession while the villagers are rejuvenated and reborn with the ideas their object of loss has created within their minds.

\section{Conclusion}

Burial and The Handsomest Drowned Man in the World are from various eras, cultures and countries, yet they string together several common human needs. As shown in this study both stories circulate around a lack; an entity is missing for both sets of characters. Each through their own psychological pattern find a way to place themselves in a path of change. Maliheh's quick notice of the sound of the siren and the village children's shouts on a new body on shore act as indicators that a new change is coming. While the villagers fantasize about the possibilities of this great body on their land, Maliheh knows what she can do with the child's corpse. Maliheh physically and mentally struggles as she aims to find a corpse to own to give her a sense of life. The villagers reach ownership later than Maliheh as they spend time fantasizing and allowing their new found corpse to gradually expand their horizons. When the grey funeral of the child's corpse is held in Burial it acts as a confirmation to Maliheh's identity, allowing her to gain stability and thus indicating the navigation from lack to stability. The villagers follow the same passage of sense of lack to rejuvenation; they hold a ceremony to acknowledge their great Esbatan and rejoice his union with the villagers.

Each story depicts human needs, the paths they choose and the changes they reach differently. Neither story surpasses the other much in the same way no way of grieving is more recommended than the other. The short stories of Bijan Najdi and Gabriel Garcia Marquez depict different human desires. They show characters struggling to find their way and highlight the concern and confusion that occurs. The Burial and The Handsomest Drowned Man in the World show the passage of the characters in redefining their identities. Doing justice to psychologist Elisabeth Kübler-Ross's words, "You will heal and you will rebuild yourself around the loss you have suffered. You will be whole again but you will never be the same. Nor should you be the same nor would you want to." ( Kübler-Ross, 2014, p.196).

\section{References}

Alexander, H. (2002). Bereavement: A shared experience, 3rd Edn. Oxford: Lion.

Balaev, M. (Ed.).(2014). Contemporary approaches in literary trauma theory. United Kingdom: Palgrave Macmillan.

Boesrner, K. \& Hechkhausen, J. (2003). To have and have not: Adaptive bereavement by transforming mental ties to the deceased. Death Studies, 27(3), 199-226.

Freud, S. (1917). Mourning and melancholia. J. Strachey (Ed.). The complete works of Sigmund Freud (Standard Edition). London: Hogarth Press.

Fosha, D. (2001). Trauma reveals the roots of resilience. Constructivism in the Human Sciences, 6( 1 \&2), 7-15.

Garcia Marquez, G. (1972). Leaf storm and other short stories. (Gregory Rabassa, Trans.). New York, NY: Harper and Row.

Genosko, G. (2001). Deleuze and Guattari: Critical assessments of leading philosophers. London: Routledge.

Kubler-Ross, E. (2014). On death and dying. New York, NY: Scribner.

Mallon, B. (2008). Dying, death and grief: Working with adult bereavement. New York, NY: SAGE Publications Ltd.

Najdi, B. (2013). The Leopards who Have Run with Me. Tehran, Iran: Nashr-e-Markaz.

Salehi ,B. \& Farizani , S.B. (2016). The study of poetic language of Bijan Najdi and the structure of A pool full of nightmare. EuropeRevue Litteraire Mensuelle, 1, (133-139).

Van Dyne, L. \& Pierce, J. (2004). Psychological ownership and feelings of possession: three field studies predicting employee attitudes and organizational citizenship behavior. Journal of Organizational Behavior, 25, 439-459.

Vannoy Adams, M. (2014). For love of the imagination: Interdisciplinary applications of Jungian psychoanalysis. East Sussex: Routledge. 
Walter, T. (1996). A new model of Grief: Bereavement and biography. Mortality,1, 7-25.

What's (2015, December 15). What's new with the work of Bijan Najdi?. Retrieved from http://www.isna.ir/news/ 94092413794

Zelenko, M. \&Benham, A. (2002). Attachment theory, loss and trauma: A case study. Clinical Child Psychology and Psychiatry, 7, 199-

209. 